04 a 07 de outubro de 2016 Belo Horizonte - MG
Blucher Design Proceedings

Outubro, 2016 | num. 2, vol. 9

proceedings.blucher.com.br

\title{
TAPETNIAS: O DESIGN DE UM JOGO DE INTERAÇÃO NO CONTEXTO DAS RELAÇÕES ÉTNICO RACIAIS
}

Jucelia S. Giacomini Silva, Dra .

Instituto Federal de Santa Catarina

jucelia.giacomini@ifsc.edu.br

Samantha Gollnick

Instituto Federal de Santa Catarina

samanthagollnick@gmail.com

Amanda Guesser Nazário

Instituto Federal de Santa Catarina

guessernazario@gmail.com

Debora Eloise Sperandio

Instituto Federal de Santa Catarina

debsperandioo@gmail.com

Resumo: O presente artigo descreve o desenvolvimento de um jogo, voltado para o público infantil, a fim de permitir conhecer melhor as diferenças e desconstruir os preconceitos de papéis e relações sociais de discriminação étnico-racial. Este jogo foi desenvolvido para crianças e orientado para o lazer, e também para o ensino dos diferentes aspectos culturais relacionados à discriminação étnica, inserindo a criança dentro do contexto que envolve estas questões. O projeto foi realizado a partir de pesquisa bibliográfica que embasou a fundamentação teórica sobre os temas em questão e pesquisa de campo, realizada por meio da aplicação de questionários com o público-alvo, entrevistas com profissionais da área educacional, culminando no desenvolvimento de um jogo que trata das relações étnico-raciais de maneira simples e lúdica, buscando tornar o contato com essas questões mais dinâmico e divertido.

Palavras-chave: Jogo de interação. Design e Cultura, Etnias, Cultura Negra, Educação contra o Preconceito.

Abstract: This article describes the development of a game directed to children in order to allow a better understanding of differences and to deconstruct the prejudice in relation to ethnic and racial discrimination in social roles and relations. The game was developed for children and is oriented for recreation and also for the learning of different cultural aspects related to ethnic discrimination, including the child in a context that involves this issues. The project was based on a bibliographical research, which supported the theoretical foundation of the matters in question, and on the field 
research which was implemented through the application of questionnaires to the target group and interviews with professionals of the education area. The process resulted in a game that deals with ethnic-racial relations in a simple and playful way, aiming at making the contact with this issues more dynamic and fun.

Keywords: Interaction game; Design and Culture; Ethnicities; Black Culture; Education against prejudice.

\section{INTRODUÇÃO}

O acelerado processo de globalização é um fator que vem determinando os caminhos percorridos pela sociedade e ocasionando diferentes níveis de padronização e diversificação socioculturais. Segundo Ono (2004, p. 55) a globalização constitui-se em "um processo em desenvolvimento, que surge e se amplia de forma desigual e contraditória, dentro do processo histórico, social, econômico, político e cultural, através de um complexo de forças que atuam em diferentes esferas da realidade". Simultaneamente a esse processo observa-se a ampliação de algumas manifestações de "afirmação de etnicidade" e consolidação de diferenças, sendo que algumas dessas diferenças se corporificam como preconceito étnico-racial e constituem um dos lados intrincados das relações sociais vigentes na atualidade (GUEDES, MENEGUZZI, 2008, p.212). Tendo em vista ampliar o aprendizado infantil sobre as diferentes etnias que constituem a nação brasileira e minimizar as diferença associadas ao preconceito étnico-racial, esse tema foi explorado ao longo do desenvolvimento deste projeto, por meio da fundamentação teórica e da pesquisa de campo, visando o desenvolvimento de um jogo educativo que amplie o aprendizado das crianças em relação ao tema em questão.

Segundo as Diretrizes Curriculares Nacionais para a Educação das Relações ÉtnicoRaciais (2004), políticas públicas, institucionais e didáticas vêm sendo implementadas pelo Estado, visando reparações, reconhecimento e valorização da identidade, da cultura e da história dos negros brasileiros. Para tanto, a discussão da diversidade deve ser trabalhada desde o período da infância, pois se a criança não for preparada desde cedo, os possíveis preconceitos presentes em seu meio dificilmente serão rompidos, fazendo com que aconteça, no futuro, a repetição dos padrões que aprendeu (SANTOS, COSTA, 2010, p. 1). Sustentando-se nestes pressupostos, o projeto exposto nesse artigo, baseou-se na asserção de que o reconhecimento das diferenças étnicas, bem como a valorização da identidade e dos aspectos culturais dos povos, nas fases iniciais do desenvolvimento infantil é determinante para a elaboração de conhecimentos, atitudes e valores que formem cidadãos capazes de compreender e valorizar as diferentes identidades que compõem a nação brasileira.

A brincadeira na infância facilita a aprendizagem física e intelectual, sendo uma ferramenta significativa para o desenvolvimento cognitivo da criança. Durante a brincadeira, a criança adquire um relaxamento psicológico, o que facilita a aquisição de novos esquemas de aprendizagem e significações (SANTOS, 2014, p. 22). Deste modo, a criação de um jogo/brinquedo que se fundamenta no ato de brincar e propicia conhecimento a respeito das diferenças étnico-raciais pode auxiliar na desconstrução de preconceitos e inserir a criança em um cenário de relações sociais tangíveis. Quando o ato de brincar acontece, ocorre também o desenvolvimento de capacidades emocionais, intelectuais, motoras, físicas, sociais e culturais. 
O método utilizado para o desenvolvimento deste projeto consistiu na realização de pesquisa bibliográfica, que embasou a fundamentação teórica sobre os temas em questão e pesquisa de campo, realizada por meio da aplicação de questionários com o público-alvo e entrevistas com profissionais da área educacional. Como resultado tem-se o desenvolvimento de um jogo interativo e educativo que busca inserir as crianças em diferentes contextos culturais e identitários.

\section{RELAÇÕES ÉTNICO-RACIAIS}

O modelo de desenvolvimento excludente firmado no Brasil ao longo de sua história colaborou para a segregação e preconceito enfrentados pelos diferentes povos que constituem a nação brasileira e, de modo mais direto pelos afrodescendentes. Segundo as Diretrizes Curriculares Nacionais para a Educação das Relações Étnico-Raciais (MEC, 2004), o ensino da história e da cultura desses povos tem como objetivo o reconhecimento e valorização da identidade, a garantia de reconhecimento e igualdade de valorização das raízes africanas da nação brasileira, ao lado das indígenas, europeias e asiáticas, bem como outras inseridas no contexto cultural brasileiro.

O reconhecimento de situações de preconceito deve constituir-se através da justiça e iguais direitos sociais, civis, culturais e econômicos, mas, a valorização da diversidade, pode ser ensinada através da história e cultura negra, caminho para a desconstrução de discursos, raciocínios e posturas encontrados em grande parte da sociedade.

"Reconhecimento requer a adoção de políticas educacionais e de estratégias pedagógicas de valorização da diversidade, a fim de superar a desigualdade étnico-racial presente na educação escolar brasileira, nos diferentes níveis de ensino" (MEC, 2004, p.12).

A criação de políticas de reparação, desenvolvidas por movimentos brasileiros, como por exemplo, o Movimento Negro Unificado, são voltadas para a educação dos negros, que tentam trazer garantias de que essa população permaneça e tenha sucesso na educação escolar, e, principalmente, que o patrimônio histórico-cultural africano e afro-brasileiro seja valorizado e reconhecido (MNU, 2006).

Como valorização desta cultura e de outras constituintes dos costumes brasileiros, entende-se a necessidade da criação de projetos empenhados em dignificar as histórias e a cultura de afro-brasileiros, bem como de europeus, asiáticos e indígenas.

Por meio de pesquisa dos dados históricos compilados em um relatório, foi possível à equipe desenvolvedora deste projeto visualizar o quão intrínseco se encontra o preconceito que permeia as relações sociais. Considerando o Design como uma prática que tem como uma de suas funções promover a reflexão sobre a cultura da qual participamos (NICOLAU, 2013), o mesmo deve ser exercido de forma ética, estética, consciente e responsável, estabelecendo, através da comunicação, a relação entre o ser humano e o seu entorno (FOUNTOURA, PEREIRA, 2004, p. 1).

Deste modo, algumas das atribuições relacionadas à atuação do profissional em Design consistem em compreender as relações que acontecem no entorno, investir prioritariamente na atividade de projeto, onde deve estar seu olhar central, não podendo privilegiar apenas o 
discurso de seu campo de atuação (NICOLAU, 2013, p.13). Buscando orientar a prática do design frente à problemática identificada inferiu-se que o desenvolvimento de um jogo voltado para crianças permite a ampliação do conhecimento e valorização de nossa diversidade étnicoracial e cultural.

\section{AS CRIANÇAS E O ATO DE BRINCAR}

Durante o período da infância a criança desenvolve a base para todos os tipos de aprendizagem. $\mathrm{O}$ ato de brincar, por exemplo, é uma importante ferramenta para a evolução integral do ser humano tanto no ambiente familiar, quanto no escolar, para desenvolver-se integralmente e relacionar-se consigo mesma e com o mundo, seja por aspectos físicos, cognitivos, sociais, afetivos, culturais e emocionais (BISPO, 2013, pág. 6)

Esse processo possibilita a aprendizagem, ajudando na evolução da sua criatividade, identidade, concentração, autonomia e reflexão, a capacidade de raciocinar, julgar e argumentar. O brincar preenche as necessidades da criança, levando em consideração seus interesses e provendo o instrumental necessário para avanço de seu intelecto, sendo não apenas uma necessidade, mas também um direito, descrito no artigo 70 da Declaração Universal dos Direitos da Criança, aliado à educação que diz: "Toda criança terá direito a brincar e a divertir-se, cabendo à sociedade às autoridades públicas garantir a ela o exercício pleno desse direito" (UNICEF, 1989).

A condição lúdica em meio às brincadeiras, envolve quase que totalmente o jogo, que é identificado como um fenômeno cultural muito antigo, que ocorre tanto no período da infância quanto na fase adulta, de maneiras diferentes e com funções diferenciadas. Pode ser visto como uma forma básica da comunicação infantil, a partir da qual as crianças inventam o mundo e elaboram os impactos exercidos pelos outros, que desenvolve a capacidade de compreender pontos de vista diferentes, permitindo que ela reproduza tudo ao seu redor: o cotidiano, a natureza, as relações humanas etc. (SANTOS, 2014, p. 21).

A concepção e aplicação de um brinquedo no processo de desenvolvimento da criança auxilia de forma significativa, o progresso do sistema cognitivo infantil. Visto que jogos e brinquedos educativos são ferramentas didáticas aplicadas na aprendizagem de modo que tornam a apreensão de assuntos complexos de forma mais clara, onde a mesma pode representar e encarar situações complicadas sem medo ou preconceitos que poderiam refreála, reconstruindo o passado e antecipando o futuro (SANTOS, 2014, p.22).

Segundo o livro "A brincadeira como ferramenta pedagógica" o brincar promove a exploração, possibilitando a descoberta de resoluções para eventuais questões ou problemas que a criança possa ter" (BARNABEU; GOLDSTEIN, 2012, p. 60), assim, entende-se que a criança, por meio de uma relação de interação com seus pais e educadores, fazendo uso de uma ferramenta como o jogo, pode conhecer e apreender virtudes, atitudes e diversidades culturais em seu entorno.

\section{O DESIGN COMO RESULTADO E COMO PROCESSO}

O Design é um campo que envolve a interdisciplinaridade e pode ser visto como uma atividade ou como um processo. Pode ser entendido como uma função de gestão de projetos, como atividade conceitual, ou ainda como um fenômeno cultural. É um dos meios que adiciona 
valor ao que é produzido pelo homem e é também um difusor para mudanças sociais e políticas (NICOLAU, 2013, p. 12).

Além disso, entende-se o Design como um instrumento que auxilia na formação da cultura de determinada sociedade. Os artefatos criados pelo ser humano, sendo eles produtos, elementos de comunicação visual, sistemas de produtos ou ambientes, surgiram para atender algum tipo de necessidade. Como meio de interação, o Design atua como elemento interrelacional no encadeamento das relações estabelecidas entre o ser humano e seu entorno, transformando e interferindo em seu ambiente e visando a melhorias destas relações. É por intermédio do Design e suas ferramentas que pode-se conhecer e analisar as mudanças ocorridas nos hábitos, nos costumes e na maneira de ser e de viver do ser humano numa determinada sociedade (FONTOURA, 2002, p. 70-71).

Por meio da pesquisa realizada observou-se que a compreensão da diversidade das relações socioculturais são determinantes para o processo de desenvolvimento da criança e, fazendo uso dos processos metodológicos do Design tornou-se possível estabelecer as interfaces necessárias para o desenvolvimento de jogo apresentado neste artigo, que visa propiciar conhecimento e reflexões sobre os temas abordados. Deste modo compreende-se que este produto oriundo do Design (como um resultado e como um processo), pode auxiliar as crianças a respeitar e valorizar a pluralidade do patrimônio sociocultural brasileiro, podendo assim, se posicionar contra discriminações baseadas em diferenças culturais, de classes sociais, sexo, etnia ou outras características individuais. (MEC, 2004, p. 107-108).

No caso, esta criança consegue promover e desenvolver habilidades sensoriais, exploratórias, de manipulação e identificação, emocionais e sociais (FONTOURA; PEREIRA, 2004), podendo aplicar seu conhecimentos para a disseminação e integração de uma sociedade, tornando-a melhor estruturada e inter-relacionada.

\section{O DESENVOLVIMENTO DO JOGO E SUA INSERÇÃO NO ESPAÇO ESCOLAR E RESIDENCIAL}

O valor das brincadeiras torna-se óbvio na medida em que torna-se um instrumento de ensino para as crianças compreenderem melhor o mundo em que vivem. As brincadeiras permitem às crianças observar o entorno de maneira muito mais intensa e assim, tornam-se capazes de fixar na memória e em seus hábitos muito mais do que o fariam de forma passiva (FONTOURA; PEREIRA, 2004, p.3).

Para uma melhor compreensão de como construir um jogo que trabalhasse as questões culturais e identitárias dos grupos étnico-raciais no contexto infantil foram realizadas entrevistas com profissionais especializados na área educacional. Nesta etapa da pesquisa foi compreendido como poderia acontecer o vínculo do jogo com o tema étnico-racial, integrando elementos de destaque presentes na cultura africana. A entrevista foi complementada com visita técnica e observação ao Núcleo de Estudos Afro-Brasileiros (NEAB) da Universidade do Estado de Santa Catarina, espaço que produz e dissemina conhecimento por meio do ensino, pesquisa e extensão, desenvolvendo políticas de diversidade, promovendo a igualdade e valorizando as populações e origem africana e indígena.

Para o entendimento do contexto social em que as crianças estão inseridas optou-se por aplicar questionários, selecionando-se perguntas direcionadas para quatro grupos distintos: a) sociedade em geral, b) pais, c) professores e d) crianças, totalizando em 854 respostas. A 
pesquisa com a sociedade em geral e pais, foi aplicada através de questionários construídos na plataforma online Google Forms e divulgados através de redes sociais, sendo respondida por 779 e 4 participantes, respectivamente. Para a sociedade de modo geral, o questionário teve como intuito entender se o preconceito étnico era admitido pelo grupo, se observam ou vivenciam preconceito em seu entorno e se acreditavam que o preconceito pode afetar as crianças de forma significativa. O questionário direcionado aos pais buscou investigar como acontece o diálogo dos pais com as crianças em relação à educação étnico-racial e ao entendimento da diversidade cultural, buscando também compreender como esses temas são abordados dentro de suas casas.

A fim de obter maior clareza das preferências das crianças no que diz respeito aos jogos e brincadeiras, foram visitadas duas escolas, onde questionários foram aplicados com 63 alunos de 8 à 10 anos, durante seus respectivos horários de estudo e acompanhados por professores que também responderam a um questionário, totalizando em 8 respostas. Aos professores o questionamento se baseou no comportamento das crianças em sala de aula, na observação da miscigenação das culturas, acontecimentos de racismo e/ou preconceito étnico e suas atitudes a respeito, além da maneira como o assunto é abordado com as crianças.

Para as crianças, o questionário possuía cunho didático, voltado aos temas relacionados a brinquedos e jogos, cores e gostos pessoais. Crianças maiores de 12 anos, mostraram claro desinteresse em brincadeiras, e algumas delas foram capazes de perceber o assunto com maior clareza, questionando sobre o tema abordado.

O resultado dos questionários demonstrou que há uma negação por $9.2 \%$ das pessoas em geral a respeito da percepção de preconceito étnico-racial. Verificou-se também que esta é uma temática difícil de ser abordada de maneira clara e que $50 \%$ dos pais e $37,5 \%$ dos professores que participaram do questionário evitam abordar o assunto. Embora a pesquisa com pais e professores traga importantes informações para o projeto, considera-se a quantidade de pais e professores entrevistados, insuficiente para estabelecer conclusões precisas, fazendo-se necessário realizar pesquisas mais amplas para compreender o tema de modo mais aprofundado. De acordo com as respostas obtidas, aqueles que se preocupam com os atos discriminatórios tentam, de diversas maneiras, fazer com que as crianças desconstruam padrões sociais e aceitem as diferenças e esclarecem a necessidade de um meio de ensinar assuntos complexos, como as relações étnico-raciais, de maneira clara e divertida, nos anos iniciais da infância.

A partir das conclusões da pesquisa sobre as necessidades de pais e professores e crianças foi desenvolvido o jogo interativo com base nas ferramentas metodológicas de Design, como por exemplo, painéis semânticos e imagéticos, brainstorming de ideias, desenvolvimento conceitual e desenvolvimento de protótipo.

No processo de concepção do jogo foram considerados conceitos identificados através de painéis semânticos, resultando em três principais temáticas:

1. Igualdade: relacionado à negação por parte dos membros da sociedade sobre a existência do preconceito, tornando-se latente a necessidade de introduzir uma ideia de reconhecimento da diversidade;

2. Alteridade: se refere ao conceito de que a existência do "eu" individual só é propiciada pelo contato com o "outro" e; 
3. Cultura: tendo como base a tentativa de aproximar as crianças da cultura dos diversos povos e etnias que compõem a nação brasileira.

Com base nestes conceitos o desenvolvimento deste projeto apresenta como finalidade auxiliar os pais e professores na reflexão sobre as questões étnico-raciais, independente do contexto em que se encontram inseridos.

\section{O TAPETNIAS}

Este jogo foi idealizado de modo a ser praticado por no mínimo duas pessoas, podendo também ser utilizado por grupos maiores de crianças, subdivididos em até quatro grupos menores, dependendo do contexto em que for aplicado.

A maneira de jogar é simples: cada criança deve pegar uma carta com um ícone (Figura 1) e procurar relacionar esta figura com os desenhos no tapete. Atrás de cada carta está uma breve explicação sobre a origem e/ou o conceito do ícone em questão, gerando discussões, perguntas e ensinamentos para as crianças.

Junto às cartas com ícones, existem fichas circulares coloridas e ao encontrar a imagem dentro do tapete, a criança deverá usar a ficha da cor referente à sua equipe para marcar a representação encontrada, recolhendo-as ao final do jogo para contabilizar os pontos. Cada ficha colorida dentro do tapete corresponde a 10 pontos, consequentemente, a equipe que acertar mais vezes os conceitos sorteados nas fichas e conseguir encontrar as imagens no tapete, ao final do jogo terá um maior número de fichas posicionadas dentro do tapete e, portanto obterá mais pontos numéricos, ganhando o jogo.

O tapete contempla um espaço de 1,6X1,6m, é confeccionado com tecido impermeável e acompanha 100 cartas ilustradas e explicações e 184 fichas coloridas, divididas em 4 cores: amarelo, rosa azul e laranja (Figura 1).

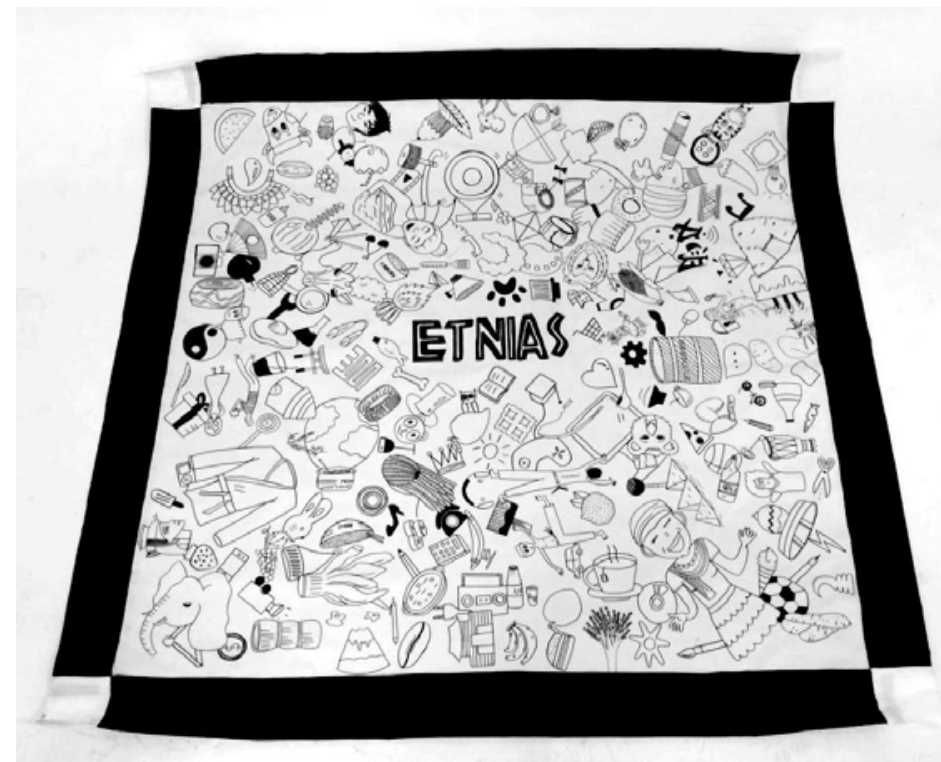

Figura 1 - Jogo Tapetnias, fichas de pontuação e cartas ilustradas

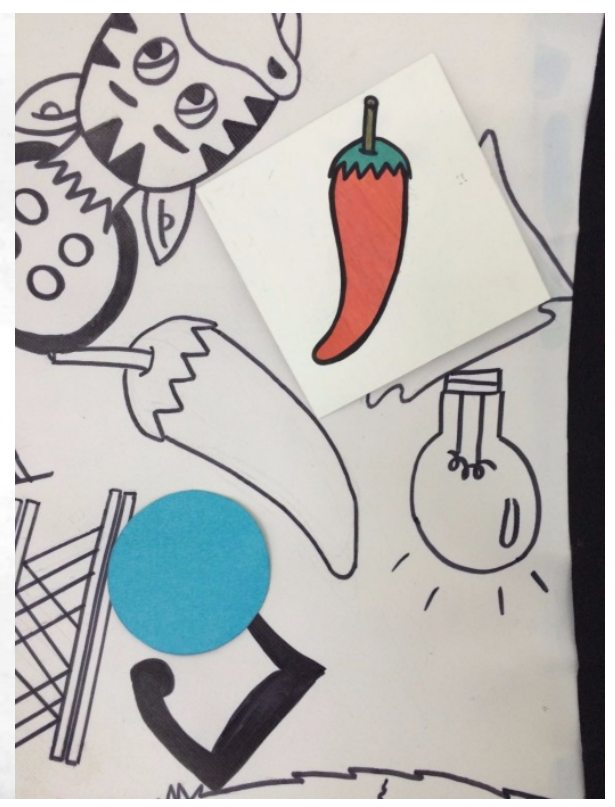

Fonte: Elaborado pelos autores (2015). 


\subsection{Considerações sobre o Tapetnias}

Alguns aspectos que devem ser levados em consideração quanto às melhorias para um desenvolvimento completo do jogo em um segundo momento da pesquisa:

1. O jogo necessita ainda de um estudo iconográfico aprofundado e detalhado para melhor esclarecer e ilustrar os elementos culturais representantes de cada cultura, a fim de evitar ambiguidades e exclusões.

2. Os significados e nomes, descritos no verso de cada carta em que são representados os ícones das culturas citadas neste artigo, necessitam de uma pesquisa mais aprofundada em fontes fidedignas e consultas com especialistas da área, a fim de promover um verdadeiro entendimento a respeito das diferentes culturas. É importante considerar que alguns ícones presentes nas cartas possuem nomes diferentes, que variam entre as diversas regiões do país.

3. O jogo necessita ser utilizado como um instrumento para a explicação das culturas representadas nas imagens ilustradas no tapete: brasileira, africana, asiática, indígena e europeia. Como as cartas não possuem espaço para uma explicação completa e aprofundada, a mesma deve ser reforçada durante a explicação de conteúdos por parte dos pais e educadores.

\section{CONSIDERAÇÕES FINAIS}

Com base no desenvolvimento deste projeto constatou-se que o preconceito e a discriminação étnico-racial, firmados historicamente no contexto sociocultural brasileiro, ainda se encontram intimamente entrelaçados nas relações sociais atuais.

Percebeu-se a necessidade de criação e disseminação de novas formas de transmissão de valores e ensinamentos, uma vez que essa discriminação é transmitida de forma intrínseca e imperceptível nas fases iniciais e primordiais do desenvolvimento infantil, através das vivências particulares de cada criança e do convívio social.

Como uma abordagem didática na tentativa de diminuir o preconceito existente é importante lançar mão de formas interativas de aprendizado sobre as questões identitárias e culturais, fazendo uso de jogos e brinquedos que eduquem as crianças contra os preconceitos latentes nos grupos sociais em que estão inseridas.

Assim, a importância da utilização do Design na elaboração de artefatos mostra-se clara quando um jogo interativo para crianças, como o Tapetnias - pensado e fundamentado com base em ferramentas metodológicas e práticas do campo do Design -, busca promover reflexões e mudanças de comportamentos nas crianças, suscitando-as para a formação de hábitos e relacionamentos respeitosos dentro da sociedade.

Por este motivo, a criação de um jogo como o apresentado neste projeto é significativo, porque além de ensinar vivências, valores e tradições de culturas presentes na sociedade brasileira, busca auxiliar pais, professores e educadores a instruírem as crianças no entendimento de que nosso país é composto por uma multiplicidade cultural e, dentro desta multiplicidade, as pessoas e seus princípios necessitam ser respeitados de acordo com suas singularidades. 


\section{REFERÊNCIAS}

BAMPI, Amélia. O Direito de Brincar. 2014. Disponível em:

<https://fundacaoabrinq.wordpress.com/2014/05/26/o-direito-de-brincar/>. Acesso em: 09 jun. 2016.

BERNABEU, Natália; GOLDSTEIN, Andy. A brincadeira como ferramenta pedagógica. São Paulo: Paulinas, 2012.

BISPO, Rose Alves. A IMPORTÂNCIA DA LUDICIDADE NA ALFABETIZAÇÃO. 2013. 42 f. Monografia (Especialização) - Curso de Especialização em Educação Infantil e Alfabetização, Ajes, Mato Grosso, 2013. Disponível em:

<http://biblioteca.ajes.edu.br/arquivos/monografia_20130523083851.pdf>. Acesso em: 09 jun. 2016.

COSTA, Esp.Olga Helena; SANTOS, Anderson Oramísio. Relações étnico-raciais na educação intantil: Implementação da lei 10.639/2003. 2010. Palmares Fundação Cultural.

FONTOURA, Antônio M.; PEREIRA, Alice T. C. A criança e o design - aprender brincando. In: Anais do 6을 Congresso Brasileiro de Pesquisa e Desenvolvimento em Design. São Paulo: FAAP, 2004.

FONTOURA, Antônio Martiniano. EdaDe: A educação de crianças e jovens através do design. 2002. 357f. Tese (doutorado) - Universidade Federal de Santa Catarina, Centro Tecnológico. Programa de Pós-Graduação em Engenharia de Produção.

GUEDES, Thiago Araújo; MENEGUZZI, Simone. Ações afirmativas e o desenvolvimento do sentimento racista numa visão etnológica. Revista do Curso de Direito da Fsg: Fsg, v. 4, 4. 2008. Semestral. Disponível em: <http://ojs.fsg.br/index.php/direito/article/view/114>. Acesso em: 08 jun. 2016.

MEC. Diretrizes Curriculares Nacionais para a Educação das Relações Étnico-Raciais e para o Ensino de História e Cultura Afro-Brasileira e Africana. Brasília: Mec, 2004. 35 p. Disponível em: <http://www.acaoeducativa.org.br/fdh/wp-content/uploads/2012/10/DCN-s-Educacaodas-Relacoes-Etnico-Raciais.pdf>. Acesso em: 06 jun. 2016.

NICOLAU, Raquel Rebouças A.. ZOOM: Design, Teoria e Prática. João Pessoa: Ideia, 2013. 201 p. Disponível em: <http://www.insite.pro.br/elivre/zoomraquel.pdf>. Acesso em: 07 out. 2016.

ONO. M. M. Design, Cultura e Identidade, no contexto da globalização. In: Revista Design em Foco, vol. I, núm. 1, julho-dezembro, 2004, pp. 53-66 Universidade do Estado da Bahia, BA. Disponível em <http://www.redalyc.org/articulo.oa?id=66110107> ISSN 1807-3778.

. Parâmetros curriculares nacionais: apresentação dos temas transversais, ética/

Secretaria de Educação fundamental. Brasília: MEC/SEF, 1997. p 25.

SANTOS, Mayara Pillegi Moura. Desenvolvendo experimentos gráficos que estimulem a criatividade na infância. Trabalho de Conclusão de Curso - Faculdade de Arquitetura e Urbanismo, Universidade de São Paulo, São Paulo, 2014. 
UDESC. Núcleo de Estudos Afro-Brasileiros (NEAB). 2010. Disponível em:

<http://www.faed.udesc.br/?id=1844>. Acesso em: 06 jun. 2016.

UNICEF. Convenção sobre os Direitos da Criança. 1989. Disponível em

<http://www.unicef.org/brazil/pt/resources_10120.htm> Acesso em: 06 jun. 2004.

UNIFICADO, Movimento Negro. Introdução. 2006. Disponível em:

<https://www.blogger.com/profile/05994186866218803389>. Acesso em: 06 jun. 2016. 